\title{
Investigation and Thinking About the First Grade Postgraduate Student Time Management
}

\author{
Mi Fu*, Xinwei Fan, Jingyu Wu, Xinran Wang, Wude Cai \\ School of Physics and Electronic Information, Yunnan Normal University, Kunming, China
}

Email address:

fumixin@126.com (Mi Fu)

${ }^{*}$ Corresponding author

\section{To cite this article:}

Mi Fu, Xinwei Fan, Jingyu Wu, Xinran Wang, Wude Cai. Investigation and Thinking About the First Grade Postgraduate Student Time Management. Higher Education Research. Vol. 6, No. 2, 2021, pp. 47-50. doi: 10.11648/j.her.20210602.13

Received: March 26, 2021; Accepted: April 8, 2021; Published: April 16, 2021

\begin{abstract}
Time utilization and time management have always been important magic weapons for students to learn and live better. It is no exception for postgraduates. Reasonably arranging schedules, making full use of time, and carrying out proper time management is a great advantage for postgraduates. The research is a one-month observation record of a first grade pedagogical postgraduate student from four aspects of study, work, life, and entertainment. Through the analysis of time management records, it found some problems, including: unreasonable allocation of study time; unreasonable allocation of scientific research time; unhealthy entertainment methods and other issues. Obviously, first grade postgraduate students are also a group that needs to be focused on, guiding them to include physical and psychological transitions, and helping first grade postgraduate students in time management, so as to make better use of time and adapt to the role of postgraduate students better and faster. The study puts forward the following three targeted suggestions: one is to change the role of psychological counseling as soon as possible; the other is to carry out research work in scientific research counseling; the third is to carry out lectures to impart time management experience. At the same time, schools and individuals should pay attention to the cultivation of time management ability. Hope this article can bring a little reference value.
\end{abstract}

Keywords: Time Management, First Grade Postgraduate, Observation Records, Suggestion

\section{Introduction}

There is a Chinese proverb: "An inch of time is worth an inch of gold." This is to remind people to cherish time and use time wisely. In the current stage of higher education, time management has always been a focus of attention, whether it is an undergraduate student or a postgraduate student. Compared with elementary education, higher education has more freedom to control time and greater autonomy for students, which also derives a series of questions about student time management [1]. From classroom study to weekend rest, from entertainment to study, whether time is used efficiently and whether time management is appropriate, to a certain extent, determines the future development of a student [2]. It is particularly important to study and think about the management and utilization of students' time.

Postgraduate education has always been referred to as elite education. After undergraduate study and baptism, entering a higher-level learning environment will inevitably face new challenges [3]. It's not only the problem of time management for domestic graduate students, but also International graduate students also have such troubles [4]. At the same time, time management is also an important factor affecting the future development of a postgraduate student [5]. How can first grade postgraduate students adapt to the change of identity better and faster, master the methods of time management, and play a role model as a graduate student. Based on this question, this research analyzed and thought about it and advise on the development and planning of postgraduate students

\section{Survey Method}

This research adopts the form of observation and recording. From the perspective of a first grade postgraduate student, one-month time management observation record was conducted. The record content is mainly divided into four sections: study, work, life, and entertainment. The recording method is as follows: Divide a total of 1440 minutes in a day, 
record according to the daily item, allow within ten minutes of error before and after. Fill in the record table on time every day, and conduct observation records for a total of one month.

Introduction to the observation object: The observation object is a first grade full-time postgraduate student in a university in Yunnan, China. No abnormality in physical health. The school's teaching work is proceeding as usual without any other impact.

\section{Survey Results and Analysis}

\subsection{Study Time Allocation and Analysis}

Study time during the first grade postgraduate students is 12,120 minutes in a month, accounting for $27.3 \%$ of the total time in a month, and about a quarter of the time is spent on learning. But more learning is not mean the course learning during the undergraduate course. $67 \%$ of the study time is self-study supplementary knowledge, including online learning of various scientific research software, browsing thesis website, etc. As shown in "Figure 1". And participating in lectures and other scientific research activities will also take up a certain amount of study time, which is very different from the study experience at the undergraduate level.
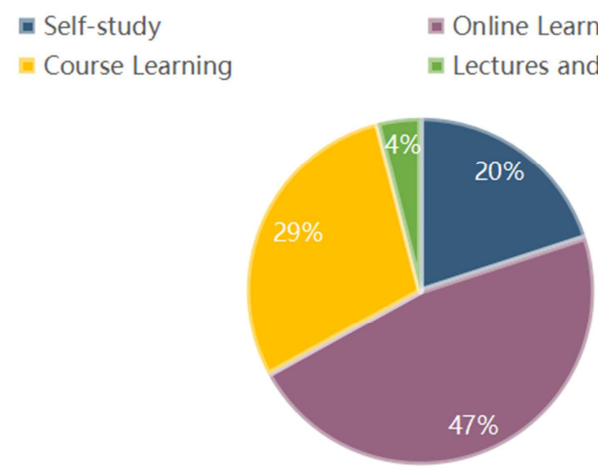

Figure 1. Distribution of learning time.

The transition from a college student to a postgraduate status will inevitably bring about a different transition of time management methods. In the time management of college students, there is generally a situation in which the goals are not clear, the time arrangement is neglected, and the time planning is unreasonable [6]. Because the focus of postgraduate training is different from that of undergraduates, relatively speaking, the first grade postgraduates have fewer courses and more spare time than undergraduates [7], on the contrary, the pressure of study (especially the cultivation of scientific research ability) will greater. In the postgraduate stage, the most essential difference is the autonomy of the learning level [8]. The undergraduate stage is led by teachers and counselors. In the postgraduate stage, The positioning of graduate students is more inclined to independent study and research, which requires the change and adaptation of identity roles. The transformation of the role of autonomous learning requires a certain process and time. This is also the main reason why some first grade postgraduate students feel that there is no time to use efficiency.

\subsection{Research Time Allocation and Analysis}

The allocation of scientific research time is also reflected in "Figure 1", where $47 \%$ of the time is spent studying and browsing online. At the same time, even though there is no arrangement for scientific research work, it is necessary to communicate with the tutor in time. In the observation record statistics, there are 930 minutes of time allocated for a month to exchange scientific research experience with the supervisor, which can be found in "Figure 2". Although there is no arrangement for scientific research experiments at this stage, the preparation time and communication time are about $7: 1$, which can ensure that after a week of self-study, it must ensure that student can communicate with tutor at least once in a week, and feedback experience and progress in time. Let the tutor be able to give student some suggestions and comments [9].

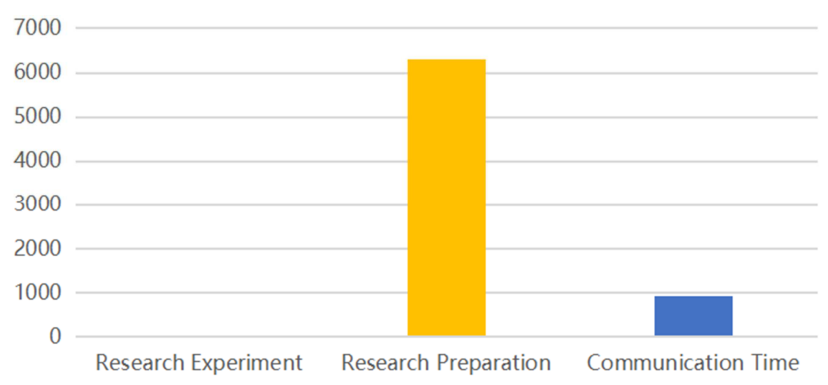

Figure 2. Distribution of research time.

In the first grade postgraduate students, They usually have not entered the laboratory work, which is consistent with the observation. The main reasons are as follows: first, students need to read a lot of literature to understand the research background and current research status at home and abroad; second, students need to find the research direction that you are interested in and suitable for you; third, students need to supplement the basic skills related to scientific research, including scientific research paper writing and the use of related software [10]. Not entered the laboratory work because the actual conditions are immature, and the large amount of free time cannot be a reason for waste and play, but to manage time and prepare for the implementation of scientific research. And also need to communicate with the instructor in time.

\subsection{Entertainment Time Allocation and Analysis}

In this research, students did not participate in student cadre work and part-time work, so the time spent in this part was 0 . And normal life time, including trivial time such as eating, sleeping, walking, cleaning accounted for the total time $51.3 \%$. The entertainment time is 6,830 minutes, accounting for $15.3 \%$, and most of the entertainment time is concentrated on weekends. Reasonable arrangement of weekend entertainment time is also a topic that colleges and universities pay attention to it [11]. The time management of college students' weekend entertainment is almost the same, 
focusing on Internet entertainment, making friends and chatting, and appropriate sports [12]. Today, when short entertainment videos are rampant, more attention should be paid to the harm it brings [13]. "Entertainment first" should not become a trend, and "moderate entertainment" is a test of a person's time management and self-discipline ability. Among the main forms of entertainment activities, scraping videos accounted for $67 \%$, occupying half of the entertainment time, as shown in "Figure 3". Obviously, this is more harmful than good.

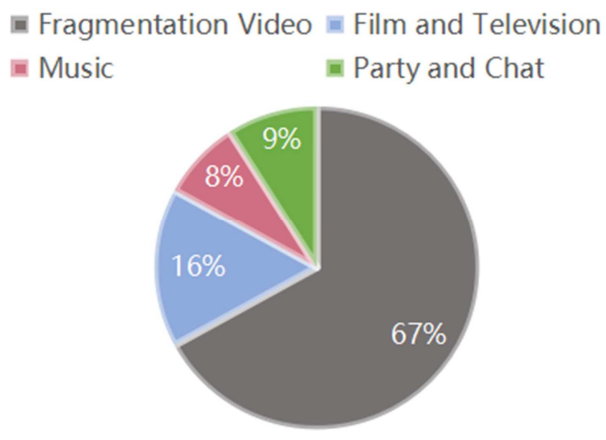

Figure 3. Distribution of main entertainment time.

Unhealthy entertainment will greatly consume students' energy, and more importantly, will lose self-discipline over time [14]. In terms of entertainment time management, abandon unhealthy entertainment activities, advocate active and sunny entertainment methods, and focus on the cultivation of self-control and time management capabilities.

\section{Suggestion}

\subsection{Psychological Counseling}

Among the first grade postgraduate students, the unsuitability of identity conversion, the confusion about scientific research, and the unknown about future development plans are objectively existing [15]. Strengthen the psychological counseling for first grade postgraduate students. First, solve the psychological problems of first grade postgraduate students and even other professional postgraduate students, and promptly help research freshmen to get out of confusion, adapt to their roles, and integrate into the scientific research field as soon as possible; second, help pedagogy postgraduate students in their future work, the sensitivity of the students' psychological counseling will help students relieve their psychological anxiety. It is undeniable that most postgraduate students resist the process of psychological counseling, and because of this, it is necessary to explore a more suitable postgraduate psychological counseling model [16]. The cultivation of time management ability seems to be out of reach of psychological counseling, howerer, it is closely related. Students feel confused and at a loss. They will only spend a lot of time doing useless work or going astray. Therefore, professional psychological counseling and guidance are quite necessary.

\subsection{Scientific Research Counseling}

For first grade postgraduate students, especially sociology graduate students such as education, they do not need to enter the laboratory for specific experimental operations like science and engineering, but they also need to conduct scientific research. It is possible that some science and engineering postgraduate students will enter the laboratory to carry out basic experimental work in the first grade, but the scientific research training of sociology graduate students cannot be ignored. Basic scientific research work including literature search, literature reading, paper writing and other scientific research preparations should be carried out. Led by the student's tutor, carry out regular communication, guide students in scientific research preparations, and read relevant professional literature knowledge. At the same time, we can carry out lectures and activities on how to conduct scientific research, so that students and tutors can actively participate in it, so that first grade postgraduate students understand what scientific research is and how to do scientific research, instead of letting them go free and waste their time. There is an essential difference between postgraduate students and undergraduate students. While doing scientific research, they are also cultivating postgraduate students' time management skills, communication skills, coordination and cooperation skills, and so on.

\subsection{Time Management Counseling}

How to conduct time management skills counseling is a more difficult problem. Because this involves students' self-awareness and self-control ability, but they should not give up this part of the counseling work because of choking. There are many successful cases of time management, such as the scientific research process of some outstanding scientists, some examples of outstanding entrepreneurs, and some outstanding film and television works. These are all tools that can be used for time management skills coaching. Inviting some scientists to share lectures, inviting some outstanding alumni to share experiences, or holding a film exhibition, so that students can be influenced by them while watching film and television works. On the one hand, students will not feel disgusted and resisted. On the other hand, it can add some positive and healthy forms of entertainment. It can be said to kill two birds with one stone, and it is a program worth learning. At the same time, the cultivation of time management ability is also a compulsory course for postgraduate self-cultivation. As a postgraduate student, you must recognize this key point and cultivate your own abilities. Increasing the use of fragmented time, reading some books, and reducing unnecessary entertainment are all ways to improve yourself.

\section{Concluding}

Time management is a profound knowledge. The cultivation of time management ability cannot be completed overnight. This research is aimed at a certain group of a certain university in a certain area. It is just a small example, but it is a 
microcosm of time management issues. There are many shortcomings and defects in this research that need to be improved. But the most important thing is that whether it is a postgraduate student or an undergraduate student, whether it is a researcher or an individual, all should pay attention to the cultivation of time management ability. Pay attention to it, study it, and practice it!

\section{References}

[1] Liu X. (2020). Thinking on the Rational Use of Spare Time by College Students. The Guide of Science \& Education, (09): 182-183.

[2] Fang R. J., Liu J. L., Wang Z. W., He H. Q., and Zhu J. J. (2020) Investigation and Reflection on the Status Quo of College Students' Weekend Time Utilization in the New Era: Taking Some College and Universities in Guangxi as An Example. Journal of Green Science and Technology, (01): 208-210+214.

[3] Zhu X. J. (2020). Research on Time Management Tendency and Test Anxiety in Graduate Students. The Theory and Practice of Innovation and Entrepreneurship, 3 (09): 149-150+171.

[4] So Hee Hyun. (2019). International Graduate Students in American Higher Education: Exploring Academic and Non-academic Experiences of International Graduate Students in Non-STEM fields. International Journal of Educational Research, 96: 56-62.

[5] Chen Q. (2015). The Among of Time Management Disposition, Personality Traits and Competence Characteristics in Graduate Students. Hunan Normal University, pp. 5-10.

[6] Chen Y. X. (2020). The Characteristics of College Students' Time Management and Improvement Strategies. Survey of Education, 9 (21): 84-86.
[7] Chen X. Y. and Zhang C. Y. (2016). Investigation and Consideration on College Students' Spare Time Management: Taking Yunnan Agricultural University as an Example. Journal of Yunnan Agricultural University (Social Science), 10 (03): 76-79+86.

[8] Wang L. L., Wen B., Liu H., Zhang K., and Bi Z. Q. (2020). Analysis on the Differences of Undergraduate and Postgraduate Education. Education Teaching Forum, (37): 72-74.

[9] Li T. (2020). How to Search and Read Documents Effectively. China Postgraduates, (08): 45-47.

[10] Wu X. (2020). Classical Reading and the Cultivation of Question Consciousness of Liberal Arts Graduate Students. Higher Education Forum, (07): 62-63+87.

[11] Duan J. H. (2015). Exploring the Countermeasures of College Students' Weekend Life Management. Asia-Pacific Education, (36): 243 .

[12] Liang J. R., Li X. K., Liu J. Y., Nie S. Q., and Zhang L. (2019). Investigation and Countermeasures of the Current Situation of University Students' Weekend Activities: Taking Universities in Chongqing University Town as An Example. Journal of Green Science and Technology, (07): 260-263.

[13] Hao H. X. (2019). Time-fragmented "Full Use": How College Students in the Era of Short Videos Seek Advantages and Avoid Disadvantages. Journal of News Research, 10 (19): 218-219.

[14] Chang J. (2019). Information Self-discipline in the Era of Short Video. Youth Journalist, (22): 27.

[15] Yang J., ang Lu Y. (2019). Probe into the Psychological Guidance Model of Postgraduate Peer. Young Society, (17): 184-185.

[16] Wu C. S., Zhang J., and Yong S. Q. (2018). Research on the Modelization of Psychological Health Education for Postgraduates. China Postgraduates, (03): 73-75. 